\title{
TÍTULO: UM ESTUDO SOBRE A IMPORTÂNCIA DO SETOR BRASILEIRO DE REFINO A PARTIR DA ANÁLISE INSUMO-PRODUTO
}

\author{
Autores: Valéria Silva Mortari ${ }^{1}$ e Cássio Garcia Ribeiro ${ }^{2}$.
}

RESUMO: A Petrobras responde por $99 \%$ da produção de produtos derivados de petróleo no Brasil. Logo, as decisões da empresa são determinantes para a configuração do setor e, consequentemente, decisivas do ponto de vista da oferta de combustíveis fósseis em um país cujo modal predominante é o rodoviário. Diante da crise atual vivenciada pela empresa, entre as estratégias encontradas pela atual direção para reverter esse quadro destacam-se as seguintes: i) redução substancial de investimento no segmento de refino; ii) anúncio da intenção de se desfazer de ativos nesse setor; iii) alteração na política de preços de combustíveis (com reajustes diários). Pode-se dizer que a greve dos caminhoneiros e a crise de desabastecimento mostraram de forma inequívoca a importância de se analisar as estratégias do governo do país e da Petrobras em relação ao setor de refino. Pretende-se neste artigo apontar a importância relativa desse setor, a partir do método de análise insumo-produto, em termos de encadeamentos produtivos, com base do cálculo de seus índices de ligação, multiplicador de emprego e produto. Os resultados apontam que o setor de refino é responsável pela geração de $10 \%$ e $18 \%$ do valor adicionado e da formação bruta de capital fixo, respectivamente, da indústria de transformação brasileira. Além disso, dado seus encadeamentos produtivos é o setor, dentre todos os setores da economia brasileira, com o maior multiplicador de emprego, de produção e índice de ligação a jusante. Nesse sentido e considerando a crise atual, percebe-se, de um lado, a importância do setor de refino para o país e, de outro, vislumbram-se consequências desastrosas (à economia e sociedade brasileiras) decorrentes das decisões da Petrobras nesse setor, tornando o país dependente da importação de derivados de petróleo e muito suscetível a oscilações cambiais.

Palavras-chave: Brasil, Petrobras, refino, matriz insumo-produto.

\section{TITLE: A STUDY ON THE IMPORTANCE OF THE BRAZILIAN REFINING SECTOR FROM THE INPUT-OUTPUT MATRIX}

ABSTRACT: Petrobras accounts for $99 \%$ of the production of petroleum products in Brazil. The decisions of the company are decisive for the configuration of the sector and consequently decisive from the supply of fossil fuels in a country whose predominant modal is the road. In the face of the current crisis experienced by the company, among the strategies found by the current direction of the company to reverse this framework are the following: i) substantial reduction of investment in the refining segment; ii) announcement of the intention to dispose of assets in that sector; iii) change in the policy

\footnotetext{
${ }^{1}$ Mestranda no Programa de Pós-graduação em Economia (PPGE) da Universidade Federal de Uberlândia (UFU).

2 Professor do Instituto de Economia e Relações Internacionais (IERI) da Universidade Federal de Uberlândia (UFU).
} 
of fuel prices (with daily adjustments). The strike of the truckers and the crisis of shortage showed the importance $f$ analyzing the strategies of the Government of the country and Petrobras about the refining sector unequivocally. It is intended in this article to point out the relative importance of this sector, from the method of product analysis, regarding productive threads, based on the calculation of its connection indices, job multiplier, and product. The results point out that the refining sector is responsible for the generation of $10 \%$ and $18 \%$ of the added value and the gross fixed capital formation respectively of the Brazilian processing industry. Moreover, given its productive threads is the sector, among all sectors (primary, industrial and services), with the most significant multiplier of employment, production, and index of downstream connection. In this sense and considering the current crisis, one can perceive the importance of the refining sector for the country. Besides this, there is a vision of disastrous consequences (to the Brazilian Economy and Society) due to the reduction of Petrobras' performance in this sector, making the country dependent on the import of petroleum derivatives and very susceptible to currency fluctuations.

Key-words: Petrobras, refining sector, investment, input-output matrix

Área 1. Indústria e competitividade; 1.1 Dinâmicas industriais setoriais e dos sistemas de produção

\section{JEL: L600 (Industry Studies: Manufacturing: General)}

\section{INTRODUÇÃO}

A trajetória da indústria petrolífera brasileira se entrelaça com a história da Petrobras. Tal companhia foi criada pelo governo federal brasileiro em 1953, com o objetivo de reduzir as restrições ao processo de industrialização do país, em vista das limitações em termos de recursos petrolíferos. As parcas reservas de petróleo em áreas terrestres impeliram a Petrobras a direcionar esforços para a atividade de exploração de petróleo no mar. A partir desses esforços foram descobertas grandes jazidas em águas profundas, na Bacia de Campos, obrigando a empresa a se capacitar para o desafio representado pela produção de petróleo nessas condições. Pode-se afirmar que a Petrobras superou tal desafio, pois além de ter logrado aumentar significativamente a produção brasileira de hidrocarbonetos, passou a ser reconhecida internacionalmente como uma das empresas petrolíferas mais capacitadas para a exploração e produção de petróleo e gás natural em águas profundas.

Outro aspecto que evidencia a importância da Petrobras no processo de desenvolvimento do país, diz respeito ao papel de suas aquisições de bens e serviços na formação e consolidação de uma indústria para-petroleira doméstica. Não obstante a pertinência das críticas direcionadas a tal política, fato é que tanto durante o período de industrialização por substituição de importações, como, mais recentemente, com a adoção da política de conteúdo local, as aquisições de bens e serviços repercutiram fortemente sobre o nível da atividade econômica doméstica, impactando, sobretudo a indústria de construção naval brasileira.

Cabe observar que mesmo após a quebra do monopólio estatal nos anos noventa, a Petrobras se mantém como o principal player deste segmento no país, respondendo por um total de $81 \%$ da produção de petróleo e por $99 \%$ da produção de produtos derivados de petróleo que atendem em grande parte a demanda doméstica (ANP, 2017). O setor, 
assim como a empresa são de fundamental importância para o país no que se refere à geração de emprego, renda e tecnologia (TAKASAGO, MOLLO, GUILHOTO, 2017).

Uma característica importante do setor petrolífero consiste na configuração verticalizada ${ }^{3}$ das grandes empresas que, no geral, atuam do poço ao posto (COSTA, 2014). Embora a especialidade da Petrobras esteja fundamentada na área de Exploração e Produção (E\&P), a fonte de valor agregado se encontra no refino do petróleo. Nesta perspectiva, o setor de refino se torna estratégico na composição do lucro da empresa, pois além de resgatar o limitado valor adicionado no upstream ${ }^{4}$, proporciona uma fonte de receitas com menor sensibilidade à flutuação internacional do preço do petróleo (COSTA, 2014).

O setor petrolífero brasileiro vive um contexto marcado pela descoberta de grandes reservatórios no pré-sal. Tal cluster permitiu um aumento significativo na produção de petróleo realizada no país, contribuindo atualmente com cerca de $50 \%$ da produção diária nacional. Pode-se afirmar que esse aumento, cria oportunidades para o Brasil se inserir entre os países exportadores de petróleo, além de permiti-lo avançar nas atividades downstream ${ }^{5}$, especialmente no refino, reduzindo a dependência de derivados de petróleo importados.

Todavia, a crise recente da Petrobras e a mudança na direção da empresa fizeram arrefecer as perspectivas otimistas descortinadas a partir da descoberta do pré-sal, provocando uma guinada nas decisões da empresa em relação ao setor de refino. Sobre a crise da Petrobras, pode-se afirmar que tal fenômeno não decorre apenas dos prejuízos atrelados à corrupção, ao contrário do que é apregoado pelo discurso hegemônico. Para uma correta interpretação dessa crise é importante que se leve em conta também o contrachoque nos preços do petróleo a partir do segundo semestre de 2014, o represamento no preço dos derivados - imposto pelo governo - que se converteram em sucessivos prejuízos para a empresa e o endividamento externo desenfreado, contratado em um cenário de alta no preço do petróleo e com o câmbio apreciado.

Diante desse cenário adverso, foram realizadas sucessivas revisões nos planos de investimento da empresa. Dentre essas revisões optou-se pela redução substancial dos investimentos no segmento de refino, bem como pela venda de ativos no setor. Concomitantemente a esse processo, observou-se uma redução no fator de utilização das plantas de refino da Petrobras e a implementação de uma nova política de preços de combustíveis adotada a partir da gestão Pedro Parente, com reajustes diários. No bojo desse processo, deflagrou-se um aumento da importação de derivados e uma expressiva alta no preço da gasolina e do diesel, estopim da crise de desabastecimento que o país vivencia por conta do movimento dos caminhoneiros brasileiros.

Diante do exposto, objetiva-se neste trabalho entender a importância do setor de refino em termos de encadeamentos produtivos, confrontando-a com a estratégia

\footnotetext{
3 " $\mathrm{Na}$ indústria do petróleo, a verticalização significa a presença tanto nas atividades upstream como downstream, permitindo a garantia de suprimento de petróleo, economias de escala pelo aumento do porte da empresa, maior valor agregado nas atividades e diversificação de investimentos [...] A integração vertical permite atenuar as flutuações conjunturais dos dois segmentos da indústria" (BARBOZA, 1996, p.27). Outra vantagem propiciada por tal estratégia é que esta logra a integração de conhecimento, ou seja, proporciona a capacidade de metamorfosear competências implícitas (tácita) ou explícitas (patente) que estão dispersas em uma estrutura física vasta e rica de conhecimento organizacional e científico. Com isso, a empresa se equipa de uma forma de organização eficaz tanto no que diz respeito a transferência como o acesso a conhecimentos complexos que estão fragmentados em competências dinâmicas e distintas (BALESTRO, et. al, 2004). Neste sentido, esta estratégia traduz-se na "habilidade de integrar esforços de diferentes atores tão importantes quanto a capacidade de inovar” (BALESTRO, et. al, p. 186, 2004).

4 As atividades que compõem o upstream na indústria petrolífera são aquelas relacionadas as fases de exploração, perfuração e produção de petróleo.

5 As atividades que configuram o downstream dizem respeito ao transporte, ao refino e a distribuição
} 
atualmente em voga de redução da taxa de utilização da capacidade instalada, aumento das importações e desinvestimentos no setor de refino. Assim, este artigo pretende elucidar os possíveis desdobramentos deste cenário no setor de refino em relação à economia do país. A metodologia utilizada se apoia no método de análise insumoproduto, análise de dados secundários e revisão de literatura.

Este artigo conta com mais quatro seções, além desta introdução. Na segunda seção é apresentado um referencial analítico, em que se objetiva elucidar o protagonismo da Petrobras na estruturação histórica da indústria petrolífera brasileira. Na subseção 2.2., explicita-se a importância relativa do setor de refino no interior da indústria brasileira em termos de valor adicionado, valor da transformação industrial e pessoal empregado, a hegemonia da Petrobras dentro desse setor e os investimentos realizados pela empresa a partir da segunda metade da década de 2000. Por fim, busca-se apresentar os principais elementos da crise enfrentada pela empresa e contextualizar como esse cenário tem repercutido sobre suas decisões de investimento no setor de refino. Feito isso, apresentase o método de análise insumo-produto a fim de ilustrar a importância do setor de refino de petróleo para a economia brasileira em termos de integração produtiva a jusante e a montante com as demais atividades econômicas no que diz respeito aos seus índices de ligação, multiplicador de emprego e de produção. A fim de analisar o impacto das mudanças nas decisões de investimentos no setor de refino pela empresa Petrobras, realiza-se no quarto tópico deste artigo uma análise de impacto por meio do uso da matrizinsumo produto. Na última seção do artigo são apresentadas as conclusões finais.

\section{REFERENCIAL ANALÍTICO}

\subsection{O PROTAGONISMO DA PETROBRAS NA FORMAÇÃO E TRAJETÓRIA EVOLUTIVA DA INDÚSTRIA PETROLÍFERA BRASILEIRA}

No Brasil, a história do petróleo se inicia na segunda metade do século XIX. A construção do setor exigia um amplo volume de investimentos, na medida em que o país se encontrava ainda nos primórdios do seu processo de industrialização. Os investimentos deveriam centrar-se não apenas na estruturação física do setor, mas também em pesquisa e na qualificação da mão de obra, até então inexistente no país. Vale destacar que o capital externo não aspirava assumir tamanho risco, enquanto o capital interno era escasso. Portanto, coube ao Estado $^{6}$, concomitante ao projeto nacional desenvolvimentista, a tarefa de mobilizar os recursos materiais e financeiros necessários ao nascimento do setor no Brasil. Compreendeu-se, então, a importância do setor para servir como base de sustentação ao modelo de crescimento vivenciado na época, ou seja, o setor tornou-se central no projeto de desenvolvimento industrial.

Assim, com o intuito de abastecer o mercado doméstico e com isso reduzir a dependência externa do país em relação ao petróleo, instituiu-se em 1953 o monopólio da União nas atividades de pesquisa, lavra, transporte e refino de petróleo e derivados exercido pela Petrobras, sociedade de economia mista criada para tal propósito. O contexto na época não era propício para que os investimentos fossem direcionados às atividades upstream, pois o preço do produto encontrava-se baixo e as pesquisas exploratórias (onshore ${ }^{7}$ ) realizadas no país não eram animadoras.

Segundo Rappel (2003) os primeiros projetos de investimentos da Petrobras apresentavam um índice de conteúdo local de $10 \%$, dado que a produção dependia da

\footnotetext{
${ }^{6}$ Esta estratégia "fazia parte de um ciclo histórico no qual se tentou montar as bases industriais brasileiras por meio da criação de estatais nas áreas de siderurgia, metalurgia e petróleo" (LUCCHESI,1998, p.22).

${ }^{7}$ Em terra.
} 
importação tanto de recursos materiais como humanos. Com o crescimento acelerado da economia brasileira nos anos 1950 e 1960 a demanda pelos derivados de petróleo se elevara continuamente, na medida em que, este crescimento se dava via processo de industrialização por substituição de importação a partir da atração de capital estrangeiro amplamente pautado na indústria automobilística. Neste contexto, inicia-se uma longa fase de investimentos nas atividades downstream.

Na segunda metade dos anos 1960 até 1980, presenciou-se a ampliação do parque de refino além de expressivos investimentos na infraestrutura necessária para o abastecimento interno. Este cenário refletiu sobre o índice de nacionalização que chegou a superar a casa de 60\%, em alguns casos atingindo 90\%. Esse esforço apresentou resultados significativos, "dentre os principais benefícios de natureza sócio-econômica alcançados, destacam-se a efetiva capacitação nacional na área da indústria do petróleo, com a consolidação de expressivo parque industrial e de serviços técnicos" (RAPPEL, 2003, p. 97).

Com os dois choques do petróleo a estratégia de investimento da Petrobras sofreu uma alteração importante, isto porque, mesmo com a quadruplicação dos preços, a demanda pelo produto se manteve elevada, representando um fardo na balança comercial do país. Tendo isso em vista, a revisão na estratégia de investimento tinha como objetivo amenizar o efeito dos choques sobre a economia doméstica.

Neste cenário se destacam as políticas que buscaram reduzir a dependência externa do país em relação a este recurso a partir da exploração de novas fontes energéticas assim como novas fontes de importação, além da busca pela valorização do petróleo nacional (PINTO JÚNIOR, et. al, 2007)

Deu-se então início a uma fase de políticas energéticas centradas na redução da dependência do insumo a partir da substituição de derivados e a diversificação das fontes de suprimento de petróleo. Barboza (1996) argumenta que neste contexto a ênfase dos investimentos no setor de refino se arrefece, dando lugar a uma etapa em que se intensifica a alocação de recursos a fim de desenvolver a capacidade produtiva brasileira no segmento de exploração e produção (E\&P), como pode ser observado pelo Gráfico 1.

\section{Gráfico 1 - Histórico do investimento relativo ao total da Petrobras em Abastecimento} e E\&P $(\%)-1970$ a 2016

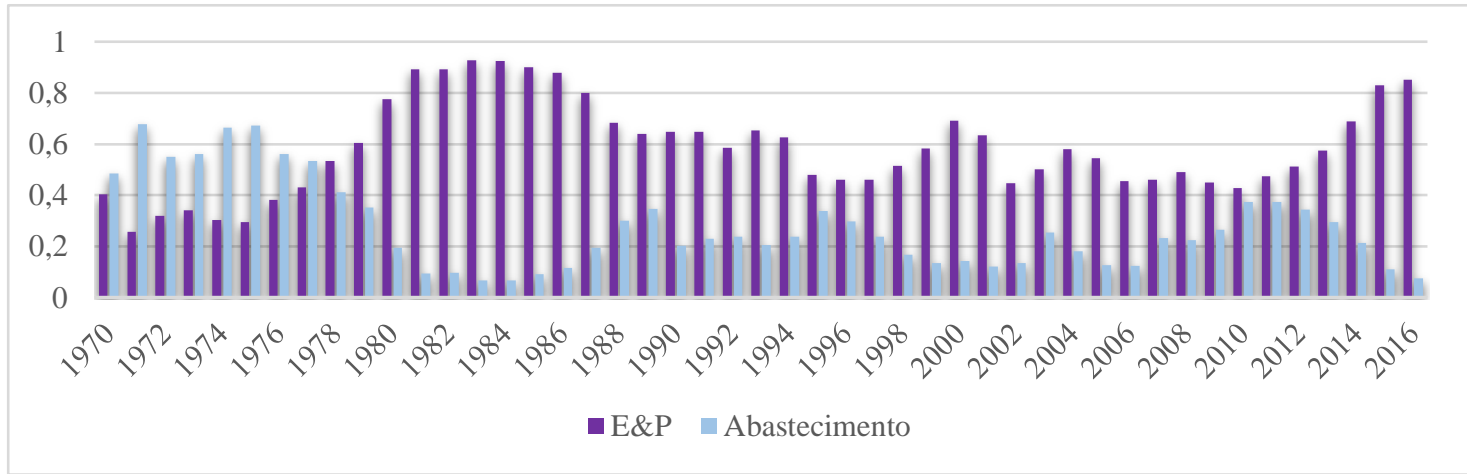

Fonte: Petrobras (2017).

Logo, os anos 1980 caracterizam-se, no que diz respeito à indústria do petróleo, pela ampliação nos investimentos em E\&P, enquanto o setor de refino foi relegado ao segundo plano, tendência que se mantém na atualidade. A partir deste cenário ocorre a ampliação dos investimentos e, portanto, da capacidade produtiva, além da intensificação em projetos de pesquisa e desenvolvimento voltados principalmente para E\&P em águas 
profundas $^{8}$. Com base nesse esforço a Petrobras alcançou uma contínua redução de sua dependência externa, consagrando-se como a maior empresa Estatal brasileira, além de obter destaque internacional, pois logrou acumular de forma contínua competências tecnológicas ao se capacitar para realizar atividades inovadoras.

A Petrobras criou forte competência em pesquisa aplicada e em engenharia básica, passando a gerar inovações em várias áreas, tanto no downstream como no upstream, e a desenvolver seus próprios projetos conceituais de sistema de produção offshore [...] utilizando tecnologia, serviços e equipamentos, em sua maioria made in Brazil (RAPPEL, 2003, p.96-98).

No entanto, a história da Petrobras sofre uma mudança importante nos anos 90 com fim do monopólio exercido pela União, por meio da Petrobras, na exploração e produção de petróleo no Brasil e a criação da Agência Nacional de Petróleo ${ }^{9}$ (ANP). A quebra do monopólio era vista como necessária à modernização do aparelho do Estado $\mathrm{e}$ da própria empresa, dado que se assistia um período em que o pensamento neoliberal era dominante no governo brasileiro. Tendo isso em vista, Felipe (2010) argumenta que a empresa passa a atender aos objetivos dos acionistas, quais sejam a valorização do capital e, portanto, amplia sua busca por eficiência e aprimoramento de sua competitividade.

A partir deste cenário, observou-se uma expansão substancial do número de reservas bem como do volume de produção no setor petrolífero brasileiro. Apesar disso, a década de 1990 foi nociva à indústria para-petroleira brasileira, na medida em que, a Petrobras se acopla à política de abertura comercial realizada, substituindo seus fornecedores internos por importações de insumos.

Face à disparidade das condições de concorrência entre as empresas doméstica e estrangeira, no que se refere ao suprimento de bens ligados às atividades de E\&P, instituiu-se uma política de conteúdo local ${ }^{10} \mathrm{com}$ o intuito de desenvolver internamente em níveis competitivos a cadeia de fornecedores deste setor. É válido dizer que esta política é implementada a partir de leilões, ou seja,

A aplicação da PCL começa nestes leilões, pois as empresas se obrigam a cumprir a cláusula de conteúdo local, um conjunto de percentuais de compras de bens e serviços no Brasil, em relação às compras totais, para diversas famílias de produto e condições de operação (PROCHNOK, 2013, p.1)

Concomitante à PCL promulgou-se o Programa de Mobilização da Indústria Nacional de Petróleo (PROMINP), de tal maneira que a Petrobras se estabelece nos anos

\footnotetext{
${ }^{8}$ Até 1980 a produção brasileira de petróleo estava concentrada em terra atingindo o número de 107 (mil b/dia), enquanto a produção marítima era de apenas 75 (mil b/dia). Com o amplo investimento na área de E\&P centrado na exploração de águas profundas a produção marítima ganha o papel de protagonista na indústria do petróleo brasileiro, aumentando em cinco vezes a produção em cinco anos e alcançando assim a marca de 392 (mil b/dia) em 1985 ao mesmo tempo em que a produção onshore foi de 154 (mil b/dia) (FURTADO, 1996). A predominância da produção de petróleo em águas profundas se mantém na atualidade, de fato no ano de 2016 cerca de $94 \%$ da produção de petróleo no Brasil foram provenientes de plataformas offshore (ANP, 2017). Além disso, é de suma importância destacar que "a etapa de exploração e produção offshore de petróleo se constitui em um dos segmentos industriais mais dinâmicos do mundo, sendo dominado por poucas empresas globais, de grande porte, que atuam como agentes decisivos na determinação das tendências tecnológicas do setor" (PIQUET, et. al, 2016, p. 46)

${ }^{9}$ Agência regulatória deste setor industrial

${ }^{10}$ Apesar de ter sido criada ainda nos anos 1990, a política não impôs uma obrigatoriedade para o uso de conteúdo local nos três primeiros anos de sua vigência (1999-2002), deixando voluntário o uso de bens e serviços nacionais. Somente a partir de 2003, sob a liderança do novo governo, a ANP modificou esta regra de não obrigatoriedade, passando a estabelecer uma proporção mínima de conteúdo local entre 30\% e $70 \%$ (AVELLAR e SANTOS, 2016)
} 
2000 como um instrumento de fomento ao desenvolvimento da indústria nacional (SILVA, FURTADO, 2006; PROCHNIK, 2013). A operacionalização da empresa se voltou, neste sentido, à revitalização e ao desenvolvimento da indústria para-petroleira nacional.

Com isso, colocou-se um desafio substancial sobre o parque de fornecedores locais em atender a demanda das operadoras em atividades em relação a prazo, qualidade e preço, isto é, instigou-se o aprimoramento da competência tecnológica e o fortalecimento da capacidade competitiva da rede de fornecedores de bens e serviços para a indústria nacional do petróleo. Apesar dos impactos positivos da política de conteúdo local à indústria para-petroleira do país, tal política não logrou alterar o cenário marcado pela reduzida capacitação tecnológica para inovar dessa indústria.

A principal fragilidade das empresas brasileiras reside na menor capacidade tecnológica. [...] A política de compras da Petrobras está ainda demasiadamente pautada pelo paradigma da substituição de importações e da ocupação do mercado interno a partir da fabricação local [...]. Ela não associa conteúdo local, com desenvolvimento tecnológico endógeno. As relações entre a Petrobras e os fornecedores nacionais se limitam às exigências de satisfazer os índices de nacionalização, mas não almejam o desenvolvimento de vantagens competitivas (De Oliveira, 2008, p.100-101).

Assim, embora as políticas apresentem êxito no que se refere ao estímulo à indústria para-petroleira doméstica, ao aumentar a integração produtiva e revitalizar alguns setores, estas não foram capazes de induzir o aprendizado tecnológico por meio de atividades inovativas. Neste sentido, as empresas brasileiras fornecem produtos de baixa complexidade tecnológica, enquanto as demais partes, peças e componentes tecnologicamente aprimorados são importados. Desta maneira, "fica claro que a PCL tem custos elevados, mas teve impacto efetivo na construção de uma cadeia fornecedora abrangente no setor" (ALMEIDA, LOSEKANN, VITTO, p.42, 2016).

É válido ressaltar que a Petrobras, mesmo após a quebra do monopólio estatal nos anos noventa, manteve-se com principal player nacional nos ramos de E\&P e de refino como expõe a Tabela 1.

Tabela 1 - Produção de Petróleo, Gás Natural e Derivados de Petróleo no Brasil:

Petrobras e demais empresas no ano de 2016

\begin{tabular}{cccc}
\hline Empresa & Petróleo (barris) & Produção de gás natural $\left(\mathrm{mil} \mathrm{m}^{3}\right)$ & Produção de derivados de petróleo (barris) \\
\hline Petrobras & $748.360 .717,70$ & $29.771 .797,60$ & $689.244 .222,07$ \\
Outras & $170.370 .299,30$ & $8.118 .652,70$ & $8.136 .856,66$ \\
\hline Total & $\mathbf{9 1 8 . 7 3 1 . 0 1 7 , 0 0}$ & $\mathbf{3 7 . 8 9 0 . 4 5 0 , 3 0}$ & $\mathbf{6 9 7 . 3 8 1 . 0 7 8 , 7 3}$ \\
\hline
\end{tabular}

Fonte: ANP (2017).

O investimento desta empresa apresentou um crescimento de $612 \%$ em termos reais entre 2000 e 2013 quando atinge seu ápice, representando cerca de $10 \%$ da formação bruta de capital fixo total do país e $2 \%$ do PIB, como mostra o Gráfico 2. 
Gráfico 2 - Participação do investimento da Petrobras no PIB e na FBCF do Brasil entre 2003 e 2014

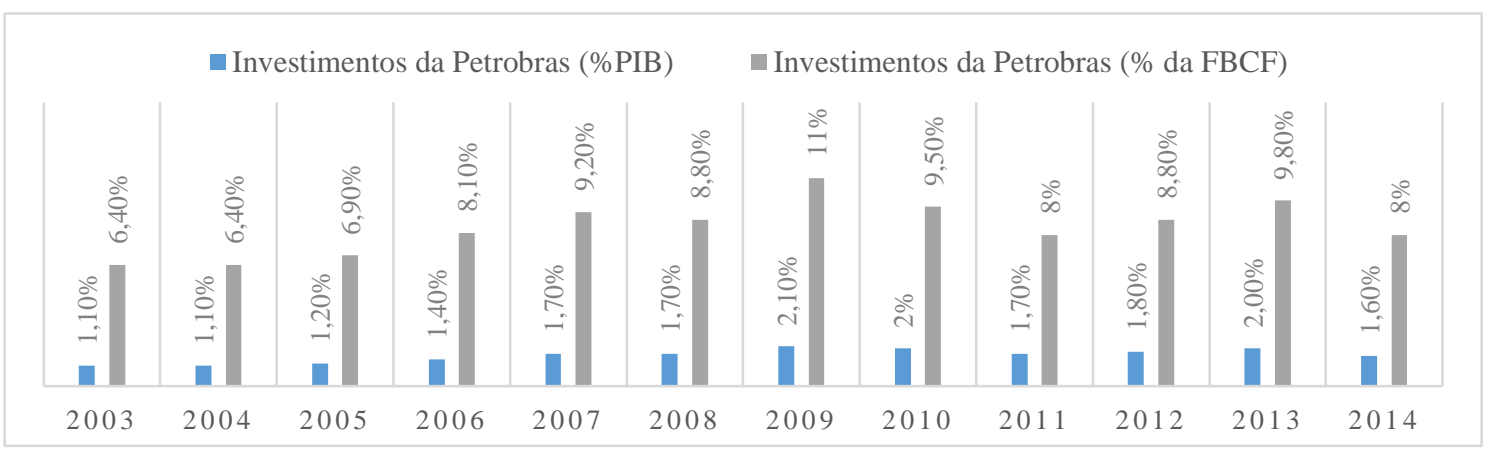

Fonte: Secretaria de Política Econômica (2015).

Além do protagonismo no mercado brasileiro, a Petrobras ocupou em 2013 a décima posição no ranking IHS Energy ${ }^{11}$, o qual lista as maiores empresas de energia do mundo. A posição de relevo da empresa no cenário internacional também fica evidente a partir dos importantes investimentos realizados em P\&D. A Petrobras é a companhia de petróleo que apresenta maior proporção de gastos com P\&D em relação ao seu faturamento, o que por sua vez, reflete na tecnologia mundialmente reconhecida na extração de petróleo em águas profundas.

\subsection{A IMPORTANCIA DO SETOR DE REFINO NA ECONOMIA BRASILEIRA}

O setor de refino constitui um segmento de importância estratégia para o desenvolvimento econômico nacional, isto porque, os produtos oriundos deste setor são amplamente utilizados no abastecimento de energia além de serem empregados no processo produtivo de outros setores como bens intermediários, tratando-se, portanto, de um setor chave tanto pela ótica de compras como pela ótica das vendas (JÚNIOR BERATELLI, et. al., 2017). O petróleo bruto pode ser utilizado apenas como óleo combustível, logo o setor de refino se responsabiliza por realizar uma série de beneficiamentos para que por meio destes se obtenha os derivados ${ }^{12}$ de interesse comercial.

A importância relativa do setor de fabricação de produtos derivados de petróleo para a indústria de transformação brasileira encontra-se exposto na Tabela 2. Por meio desta, é possível observar que este setor representou em média $15 \%$ do valor da transformação industrial e $10 \%$ do valor adicionado em relação ao total da indústria de transformação brasileira, indicando a expressividade deste setor para a agregação de valor na economia. Além disso, do total dos investimentos realizados pelos setores que pertencem à indústria de transformação, $18 \%$ diz respeito ao setor de fabricação de derivados de petróleo.

\footnotetext{
${ }^{11}$ Ver IHS Energy (2014), que engloba as mais importantes empresas de energia de capital aberto, em nível mundial.

12 Segundo Almeida (2006) os produtos resultantes das refinarias são divididos em 3 classes: 1) combustíveis - gasolina, diesel, óleo combustível, GLP, querosene, coque de petróleo, etc.; 2) produtos acabados não combustíveis - solventes, lubrificantes, graxas, asfalto e coque; 3) intermediários da indústria química - nafta, etano, propano, butano, etileno, propíleno, butilenos, etc.
} 
Tabela 2 - Média da Participação do Setor de Fabricação de Produtos Derivados de Petróleo na Indústria de Transformação Brasileira entre os anos de 2010 e 2015

\begin{tabular}{ccccc}
\hline $\begin{array}{c}\text { Valor } \\
\text { Adicionado }\end{array}$ & $\begin{array}{c}\text { Valor da Transformação } \\
\text { Industrial }\end{array}$ & $\begin{array}{c}\text { Pessoal } \\
\text { Ocupado }\end{array}$ & $\begin{array}{c}\text { Valor Bruto da } \\
\text { Produção }\end{array}$ & Investimento \\
\hline $10 \%$ & $15 \%$ & $1 \%$ & $9 \%$ & $18 \%$ \\
\hline
\end{tabular}

Fonte: PIA (vários anos).

Com exceção ao pessoal ocupado, o setor de fabricação de produtos derivados de petróleo encontra-se em segundo lugar ${ }^{13}$ em relação a todos os indicadores destacados na Tabela 2, quando se olha para o conjunto dos setores da indústria de transformação brasileira. Tendo isto em vista, é possível dizer que o setor possui uma ampla contribuição na geração de riqueza dentro da economia brasileira. Além disso, é válido destacar que, embora a variável pessoal ocupado apresente um valor reduzido, como ficará claro mais adiante, ao considerar os encadeamentos produtivos gerados pelo setor de refino, este possui o maior multiplicador de emprego dentre todos os setores da economia brasileira.

No Brasil a Petrobras, assim como na área de exploração e produção, representa o ator principal no setor de refino, na medida em que $15^{14}$ das 18 refinarias $^{15} \mathrm{em}$ atividade no país pertencem à empresa. Como destacado anteriormente, os primeiros passos dados pela petrolífera brasileira tinham como intuito alcançar a autossuficiência em relação aos derivados de petróleo, para que se fosse possível colocar em prática o projeto de desenvolvimento nacional vigente que contemplava um período de expressivo crescimento econômico. Esse foco se perde após os dois choques do petróleo, em que a empresa passa a dar maior importância relativa em seus projetos de investimento no segmento de E\&P, como ficou claro nos dados apresentados no Gráfico 1.

O protagonismo da Petrobras na área de refino se torna claro pela expressividade de sua participação na produção total de derivados no setor que chega a 99\%. É interessante destacar que a empresa prioriza o processamento do petróleo nacional. Segundo o relatório anual da empresa, em 2016, 92\% do total de petróleo processado foi proveniente de campos brasileiros (PETROBRAS, 2016).

Dado a preponderância da Petrobras no segmento de refino, seus planos de investimento ditam a configuração atual e futura do setor. O objetivo central destes investimentos consiste na construção de uma estrutura que permita o abastecimento do mercado interno, além de criar uma capacitação técnica a fim de reduzir a importação de petróleo e aumentar a agregação do valor no processamento do produto.

Nos anos 2000 pôde-se observar uma ampliação no volume de investimentos produtivos da empresa com foco na E\&P. Mais especificamente entre 2008 e 2013 o setor de refino volta a ganhar expressividade nos projetos de investimentos em termos absolutos (como pode se observar na Tabela 3 ) e relativos (como pôde ser observado no Gráfico 1). $\mathrm{O}$ aumento no volume de investimentos na área de refino está ligado ao aquecimento na demanda interna por derivados de petróleo, assim como pelo aumento na extração do produto com a exploração do pré-sal.

\footnotetext{
13 O primeiro lugar é ocupado em todos as varáveis indicadas na Tabela 2 pelo setor de fabricação de produtos alimentícios

${ }^{14}$ A Petrobras conta com 13 refinarias, uma unidade de processamento de xisto no estado do Paraná mais o Complexo Petroquímico do Rio de Janeiro (Comperj) ainda em construção.

${ }^{15}$ As 18 refinarias são: Riograndense (RS), Lubnor (CE), Manguinhos (RJ), Recap (SP), Reduc(RJ), Refap (RS), Reman (AM), Repar (PR), Replan (SP), Revap (SP), Rlam (BA), RPBC (SP), RPCC(RN), Rnest (PE), Fasf (BA), Univen (SP), Dax Oil (BA).
} 
Tabela 3 - Investimentos consolidados da Petrobras (R \$ bilhões - 2009 a 2016)

\begin{tabular}{cccccccccc}
\hline Investimentos & 2008 & 2009 & 2010 & 2011 & 2012 & 2013 & 2014 & 2015 & 2016 \\
\hline E\&P & 26,17 & 30,81 & 32,73 & 34,25 & 42,97 & 59,99 & 56,89 & 63,35 & 47,3 \\
Abastecimento & 11,99 & 16,5 & 28,46 & 27,11 & 28,86 & 30,74 & 18,26 & 10,68 & 6,64 \\
Outros & 15,13 & 16,85 & 15,21 & 11,17 & 12,30 & 13,68 & 11,97 & 2,29 & 1,66 \\
\hline Total & 53,3 & 64,18 & 76,41 & 72,54 & 84,13 & 104,14 & 87,14 & 76,32 & 55,35 \\
\hline
\end{tabular}

Fonte: Petrobras (2017).

Neste sentido, pode-se dizer que este setor experimentou uma fase de expansão de capacidade e recebeu ainda investimentos com o intuito de realizar um upgrade tecnológico no interior das refinarias. Este cenário, no entanto, se inverte, como fica claro pela queda acentuada nos investimentos direcionados ao setor, a partir de 2014, com a crise vivenciada pela Petrobras. Este contexto de crise será melhor explorado a seguir, porém é interessante não perder de vista a importância deste setor na configuração atual da indústria de transformação brasileira, como foi aqui destacado.

\subsection{CRISE DA PETROBRAS E SUAS REPERCURSÕES SOBRE AS DECISÕES DE INVESTIMENTO NO SETOR DE REFINO}

Na fase que antecede a crise, a Petrobras anunciou a construção de quatro refinarias, quais sejam: Refinaria Abreu e Lima (Rnest), Comperj, Refinaria Premium I e Premium II. É válido destacar que a Rnest iniciou suas atividades, de forma parcial, 34 anos após a construção da última refinaria construída pela empresa. Com isso, entendese que a ampliação da capacidade de refino no país ocorreu de maneira lenta e gradual.

É importante ressaltar que os dois primeiros projetos demandaram um volume de investimento superior àquele orçado. Previa-se no orçamento um volume de investimento para a construção da Renest de US\$ 2,4 bilhões. No entanto até o momento, estima-se que foram gastos US\$ 17 bilhões. No que diz respeito à construção do Comperj, tal projeto foi orçado inicialmente em US\$ 6,5 bilhões. Todavia, os investimentos nesse complexo já alcançaram a marca de US\$ 13,5 bilhões. Estes são casos que suscitaram a investigação de corrupção na empresa por meio da operação Lava-Jato, que teve início em março de 2014.

O cenário de investigação foi acompanhado pela crise política e econômica no país, além da queda no preço do petróleo ${ }^{16}$ e reavaliação dos ativos ${ }^{17}$ da Petrobras. Esta conjuntura engloba ainda um período entre 2011 e 2014 em que se empregou uma política de contenção nos preços de derivados orientada para o controle da inflação que impactou severamente na capacidade de geração de receita da empresa, decorrente da diferença entre o preço de importação e o preço de venda no mercado doméstico. Segundo Almeida, Oliveira e Losekann (2015) o impacto nocivo do desajuste nos preços praticados se tornam perceptível quando se olha para os indicadores financeiros da empresa, a partir dos quais se observa um aumento de $70 \%$ no endividamento da Petrobras entre 2011 e 2013.

Com a deflagração da crise a empresa anunciou diversas mudanças em seus planos de investimentos. Em janeiro de 2015 a empresa optou por encerrar os projetos de investimento para a construção das Refinarias Premium I e Premium II. Além disso, postergou os projetos para construção da Renest e Comperj, com base nos seguintes argumentos: i) declínio nos preços do petróleo; ii) aumento da necessidade de divisas em

\footnotetext{
16 "Desde junho de 2014 o preço do barril de petróleo vem sofrendo uma vertiginosa queda. O preço da commodity sofreu uma redução de mais de 60\% de seu valor até o fim do ano de 2015." (BASTOS, ROSA e PIMENTA, 2017).

${ }^{17}$ Segundo a Petrobras (2014) o valor de mercado da empresa reduziu 43\% entre 2010 e 2013.
} 
caixa para fazer frente a obrigações de curto prazo, dado a desvalorização do real; e iii) insolvência de empreiteiras e fornecedores (alvos da Operação Lava-Jato). Entre 2013 e 2016 os investimentos da Petrobras sofreram uma redução de 46,8\%. Na área de abastecimento esta queda chegou a 78,4\%, segundo dados da Petrobras (2017).

No Gráfico 3, pode-se observar a evolução das vendas e produção dos derivados combustíveis do petróleo assim como a utilização da capacidade produtiva das refinarias no Brasil. É possível identificar um movimento interessante, qual seja, a partir de 2007 cresce a distância entre a produção e a venda de derivados no país, concomitante a uma crescente redução da utilização da capacidade produtiva nas refinarias entre 2013 e 2017.

Gráfico 3 - Produção e venda de derivados combustíveis do petróleo (barril/dia) e fator de utilização da capacidade instalada nas refinarias brasileiras (\%)

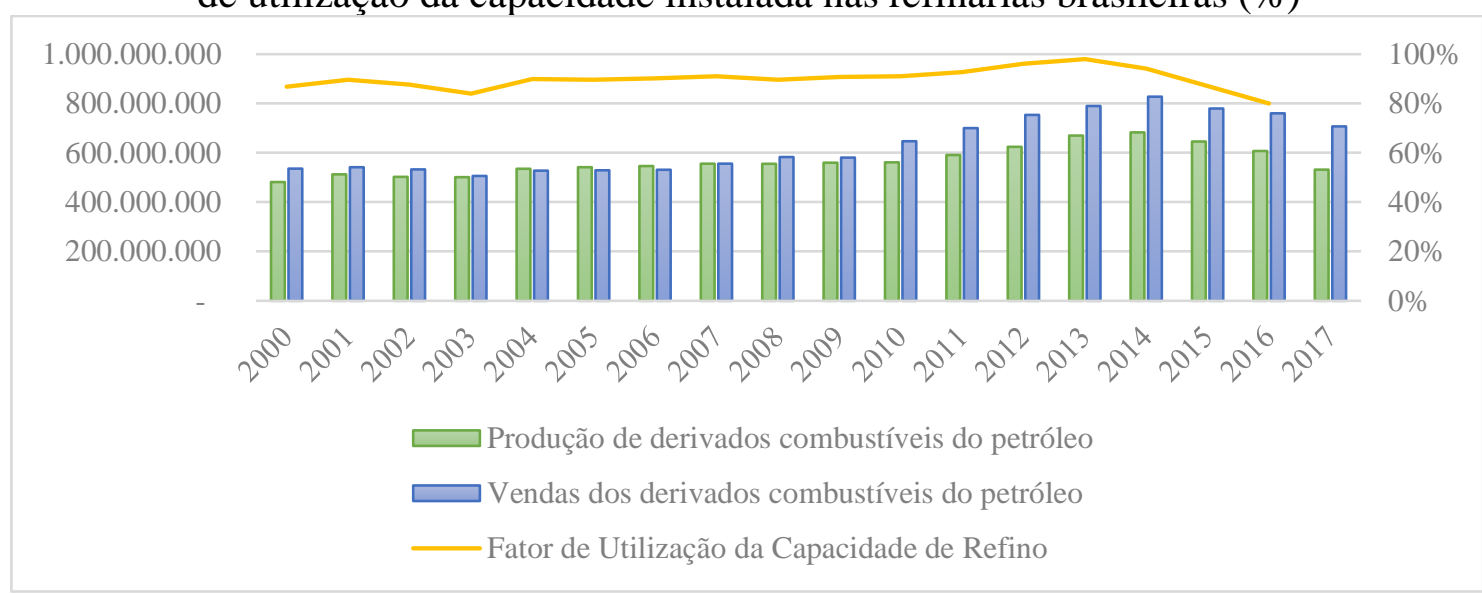

Fonte: ANP (2010; 2017).

Em que pese a necessidade de exportação de derivados, decorrente das limitações de refino impostas pelo petróleo pesado produzido nos reservatórios da bacia de Campos, é de se estranhar essa redução significativa no fator de utilização de nossas refinarias. No ano de 2016, o parque de refino brasileiro operou com folga de quase $1 / 4$ de sua capacidade. Ao operar com capacidade ociosa em seu parque de refino e adotar uma política de reajustes diários nos preços dos combustíveis, a atual direção da Petrobras incentivou a participação de derivados importados no mercado doméstico. Esse quadro trouxe ao país um contínuo déficit comercial em relação a produtos derivados do petróleo, como mostra a Tabela 4. Assim, observa-se um cenário em que, a oferta de derivados apresenta-se continuamente aquém da demanda e a produção de petróleo encontra-se em seu auge sem que isto venha resultar em uma resposta positiva no fator de utilização da capacidade de refino. 
Tabela 4 - Valores da importação e da exportação de derivados de petróleo (milhões US\$ - FOB)

\begin{tabular}{ccccccccccc}
\hline $\begin{array}{c}\text { Derivados de } \\
\text { Petróleo }\end{array}$ & 2007 & 2008 & 2009 & 2010 & 2011 & 2012 & 2013 & 2014 & 2015 & 2016 \\
\hline Importação & 6.937 & 11.173 & 5.571 & 12.980 & 19.403 & 18.151 & 19.600 & $19.475,7$ & $9.710,3$ & $8.233,4$ \\
Exportação & 7.682 & 9.873 & 5.998 & 7.055 & $9.479,9$ & 10.827 & $9.941,6$ & $9.306,2$ & $5.022,1$ & $3.536,6$ \\
\hline Saldo & 744 & $-1.300,6$ & 426,8 & $-5.924,7$ & $-9.923,4$ & -7.324 & $-9.658,8$ & -10.169 & -4.688 & -4.696 \\
\hline
\end{tabular}

Fonte: ANP (2017).

Além da redução do fator de utilização das plantas de refino brasileiras, redução abrupta dos investimentos no refino, é possível identificar na atual gestão da Petrobras uma estratégia no sentido da redução da participação da empresa setor de refino. Segundo o gerente de reestruturação de negócios, refino, transporte e comercialização da Petrobras, Arlindo Moreira Filho, pretende-se colocar à venda $60 \%$ do polo de refino do Sul e do Nordeste (Ramalho e Polito, 2018). Assim, há indícios de que a atual gestão da Petrobras, sob o comando de Pedro Parente, esteja colocando em marcha um projeto de especialização da empresa na produção de óleo cru, relegando a outras empresas e à importação o abastecimento do mercado doméstico de produtos refinados.

É possível associar as decisões tomadas pela atual direção da Petrobras no sentido da redução do fator de utilização de suas plantas de refino, a tentativa de alinhamento dos preços domésticos e internacionais de combustíveis e o incentivo à importação de derivados (em um contexto cambial pouco favorável) com a crise de desabastecimento que se abateu sobre o país. A alta no preço dos combustíveis, em especial do diesel, decorrente dessas estratégias da Petrobras, foi o estopim para a greve dos caminhoneiros brasileiros, na segunda quinzena de maio de 2018. Como o modal rodoviário é nevrálgico para o transporte de matérias-primas, mercadorias e pessoas no Brasil, a greve dos motoristas de caminhão desencadeou um verdadeiro caos na economia e na sociedade brasileiras. Pode-se dizer que a crise atual desnudou a importância do setor de refino para o país, o que reforça a pertinência da investigação apresentada neste artigo.

\section{METODOLOGIA}

\subsection{MÉTODO DE ANÁLISE INSUMO PRODUTO}

Para atender aos objetivos propostos, ou seja, analisar a capacidade de transbordamento do setor de refino de petróleo em termos de emprego, renda e produção, será utilizada a análise de insumo-produto. A teoria do insumo-produto foi desenvolvida pelo economista Leontief na década de 1930. Leontief conseguiu retratar a economia em determinado período, captando as relações contemporâneas entre os setores da economia, como se fossem partes de um único organismo (GUILHOTO, 2004). As relações econômicas assim sintetizadas constituem a matriz de insumo-produto (MIP).

A MIP trata da descrição da economia em termos de circulação, retratando-a como um sistema integrado de fluxos e transferências de insumos e produtos entre setores, sendo ela composta pela conta de produção global e é dividida em três partes. A primeira retrata a demanda intermediária, isto é, as transações de compra e venda entre os setores produtivos. A segunda é composta pelo valor adicionado, que compreende a remuneração dos fatores e o excedente bruto operacional, os impostos e subsídios incidentes sobre a produção e as importações. A demanda final, a terceira parte da MIP, é composta pelo consumo das famílias e do governo, da formação bruta de capital e das exportações. 
A partir da matriz de consumo intermediário, pode-se obter a matriz de coeficientes técnicos, que é dada por:

$$
A=\left[a_{i j}\right] \text { em que } a_{i j}=\frac{X_{i j}}{X_{j}} \text { ou } X_{i j}=a_{i j} X_{j}
$$

Para cada linha da MIP, tem-se, então, que:

$$
\sum_{j=1}^{n} X_{i j}+Y_{i}=X_{i}=\sum_{j=1}^{n} a_{i j} X_{j}+Y_{i}
$$

Em termos matriciais, $\mathrm{AX}+\mathrm{Y}=\mathrm{X}$. Com algumas operações matriciais, obtémse:

$$
X=(I-A)^{-1} Y \text { ou } X=L Y
$$

em que I é uma matriz identidade e $(I-A)^{-1}=L=[l i j]$ é a matriz inversa de Leontief, em que cada elementolij, segundo Guilhoto (2004), representa os requisitos diretos e indiretos de insumos do setor i por unidade de demanda final na produção do setor j. A equação (3) descreve o modelo básico de Leontief.

\subsection{1 ÍNDICES DE LIGAÇÃO}

Tomando como ponto de partida o modelo básico de Leontief e tendo em vista Rasmussem (1956) e Hirschman (1958) é possível calcular os índices de ligação para trás que permitem analisar a capacidade de encadeamento dos setores em sua cadeia produtiva (GUILHOTO,2004). Desta forma, a partir dos elementos da matriz inversa de Leontief definidos como $l_{i j}$ tem-se:

$$
I L T_{j}=\frac{1 / n \sum_{i=1}^{n} l_{i j}}{1 / n^{2} \sum_{i=1}^{n} \sum_{j=1}^{n} l_{i j}}
$$

Quanto ao índice de ligação para frente será empregado a metodologia de Ghosh a qual demonstra a importância de cada setor como fornecedor de insumos ao restante da economia. Considerando a matriz K:

$$
K=(\hat{X})^{-1} Z \quad \text { em que } \quad K_{i j}=\frac{z_{i j}}{x_{i}}
$$

Pode-se definir a matriz $\mathrm{G}$ como:

$$
G=(I-K)^{-1}
$$
Ghosh:

Assim, pelos elementos da matriz $\mathrm{G}$ chega-se ao índice de ligação para frente de

$$
I L F_{i}=\frac{1 / n \sum_{j=1}^{n} g_{i j}}{1 / n^{2} \sum_{i=1}^{n} \sum_{j=1}^{n} g_{i j}}
$$


Quadro 1 - Classificação setorial segundo os índices de ligação

\begin{tabular}{|c|c|c|}
\hline Índices de ligação & ILT $>1$ & ILT $<1$ \\
\hline ILF $>1$ & Setor Chave & Dependente da demanda intersetorial \\
\hline ILF $<1$ & Dependente da oferta intersetorial & Independente \\
\hline
\end{tabular}

Fonte: Adaptado de Miller e Blair (2009).

É interessante dizer que, quando o setor encontra-se classificado como setor chave, isto significa que este apresenta ampla capacidade de gerar encadeamentos, tanto para trás em sua cadeia produtiva - como demandante de insumos - como para frente como ofertante de insumos. Caso o setor seja considerado dependente da demanda intersetorial, então, pode-se dizer que este setor é um ofertante importante em sua cadeia produtiva, ou ainda, se for tido como um setor dependente da oferta intersetorial, este seria considerado como um importante demandante em sua cadeia produtiva, gerando transbordamento a montante. E por fim, caso o setor apresente ambos os índices de ligação abaixo de um, então este setor se revela como independente e possui, portanto, pouca capacidade de transbordamento produtivo.

Pela aplicação deste método será possível observar qual a abrangência do estímulo produtivo do setor de refino de petróleo sobre os demais segmentos da economia brasileira. Além disso, ao desmembrar o índice poder-se-á identificar quais são os setores que mais se beneficiam da produção de refino de petróleo, dado que o estímulo à produção neste setor não se restringe a ele próprio, mas se espraia para diversos outros.

\subsubsection{MULTIPLICADOR DO EMPREGO E DA PRODUÇÃO}

Quanto ao multiplicador do emprego, tem-se primeiramente que calcular o coeficiente direto da variável desejada, $e_{j}=\frac{E_{j}}{X_{j}}$, que mostra para cada unidade monetária produzida pelo setor $\mathrm{j}$, o quanto se gera diretamente de emprego. Para então se obter o vetor de geração de emprego $G E=e L$. Tendo em vista este processo matemático chegase a seguinte relação

$$
M E_{j}=\frac{G E_{J}}{e_{j}}
$$

Assim, o multiplicador de emprego mostra para cada emprego gerado diretamente pelo setor $j$, quanto são gerados de forma direta e indireta. Com isso, será possível quantificar quantos empregos são gerados direta e indiretamente na economia brasileira a partir da produção de uma unidade monetária no setor de refino.

O multiplicador da produção é obtido a partir do somatório da coluna da matriz L de cada setor, ou seja,

$$
M P=\sum_{i=1}^{n} l_{i j}
$$

O resultado deste somatório indica o quanto um dado setor $\mathrm{j}$, neste caso o setor de refino, ao produzir uma unidade monetária gera de transbordamento para todos os demais setores da economia de forma direta e indireta.

Este ferramental torna possível evidenciar a importância do setor sobre a estrutura produtiva do país e como seria nocivo para a economia brasileira negligenciar dentro da cadeia produtiva do petróleo o setor de refino. Destacando a sua capacidade de geração de transbordamento produtivo e, portanto, de dinamizar a economia a partir dos elos constituídos com os demais setores.

\subsection{BASE DE DADOS}


Serão utilizadas nesta pesquisa as matrizes insumo produto disponibilizadas pelo Núcleo de Economia Regional e Urbana da USP (NEREUS) para os anos de 2010 e 2013 estimadas a partir do Sistema de Contas Nacionais - Referência 2010 - as quais possuem 68 setores e 128 produtos.

\section{ANÁLISE DE RESULTADO}

Os resultados encontrados pela aplicação da metodologia exposta anteriormente encontra-se sistematizado na Tabela 5. Por esta pode-se observar qual a capacidade de transbordamento do setor de refino de petróleo e sua classificação quanto aos seus índices de ligação, além disso é possível verificar os multiplicadores de emprego e de produção deste setor, bem como o seu posicionamento dentre os 68 setores - agropecuária, indústria extrativa e de transformação e serviços - que compõem a MIP utilizada.

Tabela 5 - Índices de ligação e multiplicadores do setor de refino de petróleo brasileiro

\begin{tabular}{lccccc}
\multicolumn{7}{c}{ para os anos 2010 e 2013 } \\
\hline Indicadores & \multicolumn{7}{c}{2010} & Ranking & 2013 & Ranking \\
\hline \multirow{3}{*}{ Índice de Ligação } & Para Trás & 1,27 & 2 & 1,37 & 1 \\
& Para Frente & 2,46 & 2 & 2,48 & 2 \\
& Classificação & Setor-chave & & Setor-chave \\
Multiplicador & Produção & 2,29 & 3 & 2,46 & 1 \\
& Emprego & 76 & 1 & 72 & 1 \\
\hline
\end{tabular}

Fonte: Elaboração própria a partir dos dados disponibilizados pelo NEREUS.

Aqui percebe-se a importância do setor de refino de petróleo para a economia brasileira, dado a sua ampla capacidade de transbordamento de emprego, renda e produção, configurando-se como um setor-chave, na medida em que a sua capacidade de transbordamento intersetorial a jusante e a montante em sua cadeia produtiva é superior à média da economia. Além disso, é interessante perceber que entre 2010 e 2013 a capacidade de transbordamento deste setor aumentou, como pode-se observar na Tabela 5. A relevância econômica do setor se torna clara ao se verificar que dentre os 68 setores presentes na MIP utilizada o segmento de refino é aquele que ocupa as primeiras posições em todos os indicadores aqui analisados.

Quanto aos seus índices de ligação constata-se que sua capacidade de transbordamento intersetorial a jusante é superior aos seus encadeamentos gerados a montante na cadeia produtiva. Além disso, percebeu-se pela matriz de requerimento direto e indireto de insumos do setor de refino que enquanto as suas compras (coluna) se encontram mais concentradas, seu desempenho como ofertante (linha) está disperso em diversos setores da economia. Para melhor compreensão deste ponto, expõe-se na Tabela 6 quais são os setores que mais se beneficiam do aumento da produção do setor de refino - setores fornecedores - e quais são os setores que ao sofrer uma expansão em sua demanda final acabam por estimular direta e indiretamente a produção do setor de refino de petróleo - setores demandantes de refino. 
Tabela 6 - Ranking dos principais setores demandantes e fornecedores do setor de refino de petróleo no ano de 2013

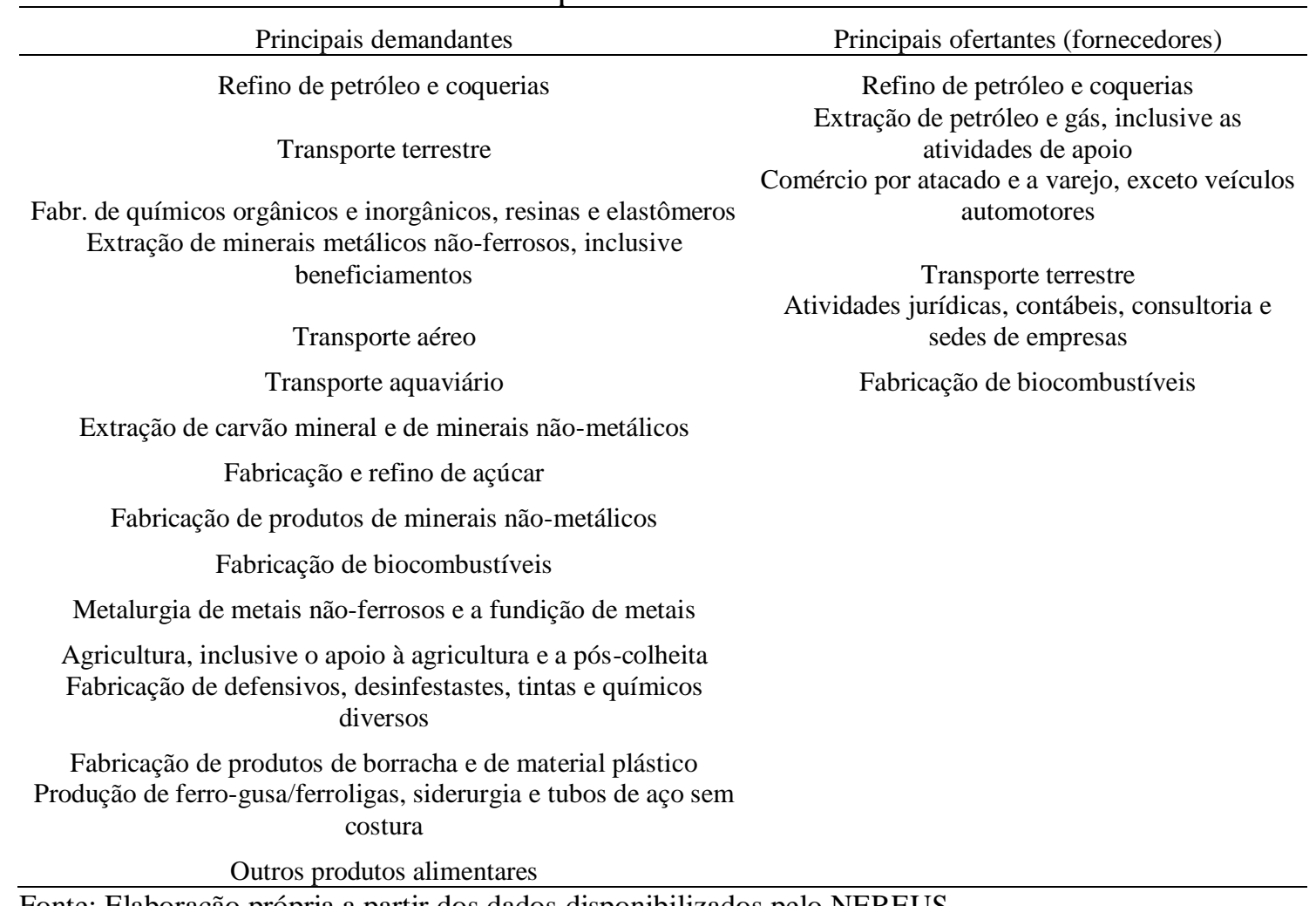

Fonte: Elaboração própria a partir dos dados disponibilizados pelo NEREUS.

Entende-se pela Tabela 6 que o setor de refino se configura como um importante provedor da demanda intermediária da economia brasileira. Assim, uma possível queda na oferta de produtos derivados de petróleo - mantendo-se a demanda constante apresentaria elevado custo para a economia. Isto porque, a demanda intermediária passaria possivelmente a ser atendida em grande medida por produtos importados, representando um peso elevado para a balança comercial brasileira.

Por fim, é possível observar que dentre todos os setores da economia brasileira o refino é aquele que apresenta o maior multiplicador de emprego. Para cada emprego diretamente gerado pelo setor gera-se outros 72 direta e indiretamente. A magnitude desse valor pode ser visto da seguinte maneira: o setor de fabricação de fumo é aquele que ocupa a segunda colocação quanto à dimensão do seu multiplicador de emprego que em 2013 alcançou um valor de 12, muito aquém daquele observado no setor de refino.

Assim, foi possível verificar como o setor de refino brasileiro se inter-relaciona com os demais setores da economia e qual a abrangência desta relação. Entende-se que o atual plano de negócios da Petrobras poderia engendrar no enfraquecimento dos elos préconstituídos pelo setor de refino além de dificultar a formação de novos. Isto por sua vez, criaria obstáculos em relação à capacidade do setor de refino de gerar estímulos/transbordamentos a outros setores através de sua demanda intermediária, assim como debilitaria o seu potencial como fornecedor de insumos abrindo espaço para que a matriz industrial brasileira preencha sua demanda intermediária a partir de importações e, com isso, transfira ao exterior parte dos transbordamentos diretos e indiretos de renda, emprego e valor adicionado.

Esta hipótese torna-se mais clara ao se observar na Tabela 7 o impacto de uma variação de $78,4 \%$ no total de investimentos realizados no setor de refino pela Petrobras entre 2013 e 2016 - como foi visto na Tabela 3. Entende-se que uma queda nos 
investimentos do setor refino refletirá diretamente sobre a sua demanda final e, portanto, produzirá efeitos negativos sobre os demais setores da economia que estão direta e indiretamente ligados a ele.

Tabela 7 - Análise de impacto sobre o PIB (em milhões R\$) e sobre o total de pessoal ocupado na economia a partir da queda na FBKF no setor de refino

\begin{tabular}{cccc}
\hline & \multicolumn{4}{c}{$\Delta \%$ no Investimento } & Efeito total sobre o PIB & Efeito sobre o emprego \\
\hline $2013-2016$ & $-78,4$ & $-420,01$ & -1.103 \\
\hline Fonte Elaboração própria a partir dos dados disponibilizados pelo NEREUS.
\end{tabular}

Fonte: Elaboração própria a partir dos dados disponibilizados pelo NEREUS.

Pela Tabela 7 é possível dizer que uma redução na magnitude de $78,4 \%$ nos investimentos de refino teria um efeito de 420 milhões de reais sobre a economia brasileira. Segundo os dados da matriz constata-se que a redução no valor de 167,68 milhões de reais nos investimentos no setor de refino teria um efeito 2,5 vezes maior sobre a contração do PIB. Este resultado produz impactos principalmente sobre o próprio setor de refino e também sobre o setor de extração de petróleo e gás inclusive atividades de apoio. $\mathrm{O}$ efeito sobre o valor bruto da produção deste último setor somaria um montante de 98 milhões de reais. Além disso, o efeito sobre o emprego chegaria ao total de 1.103 postos de trabalho extintos na economia. Se considerássemos que uma constante queda nos investimentos no setor levaria a um processo de redução no volume de sua produção e, assim, sobre o seus requerimentos de insumos, estes números poderiam alcançar valores crescentes e preocupantes.

\section{CONCLUSÃO}

A Petrobras é a empresa petrolífera que realizou as descobertas mais importantes das últimas décadas. Tais descobertas descortinam grandes oportunidades, no médio e longo prazo, para exportação de óleo bruto, mas também de óleo refinado, especialmente porque o petróleo produzido nos reservatórios do pré-sal possui qualidade superior àquele encontrado na bacia de Campos.

Todavia, a crise recente da Petrobras, a estratégia de downsizing no downstream apontam para uma inserção débil do Brasil (e da Petrobras) no setor petrolífero internacional: exportador de óleo cru e importador de derivados. A greve dos caminhoneiros e a crise de desabastecimento, com consequências graves para a sociedade e a economia do país, tornaram inequívoca a importância de estudos que se debrucem sobre a política brasileira voltada para esse setor. Considerando o aumento na produção de petróleo no Brasil (com as descobertas em sua nova fronteira exploratória) e de olho em um novo ciclo à frente, é imperioso que a estratégia para o setor petrolífero brasileiro seja repensada. Os desinvestimentos realizados na área de refino e a ausência de visão estratégica por parte do atual governo brasileiro poderão trazer consequências desastrosas para o país.

Por fim, destacam-se os impactos negativos que tal decisão estratégica, qual seja, reduzir a atuação da empresa no segmento de refino de petróleo, sobre a economia brasileira em termos de geração de renda e emprego. Por meio da análise insumo-produto foi possível identificar que este setor desempenha um papel chave na conformação da estrutura industrial brasileira, pois atua tanto como fornecedor de insumos essenciais quanto como um demandante importante na cadeia produtiva industrial. Com isso, este setor é responsável por gerar encadeamentos produtivos acima da média dos demais setores da economia, de tal forma que, a sua desestruturação poderá engendrar em efeitos irreparáveis na configuração da matriz industrial brasileira. 
Além de nevrálgico do ponto de vista do modelo de transporte predominante no país, conforme destacado neste artigo, o setor de refino tem importante impacto (a montante e a jusante) sobre a indústria brasileira. Nesse sentido, deve-se questionar as possíveis repercussões das decisões de desinvestimentos no refino anunciadas pela Petrobras sobre a economia brasileira, especialmente no que diz respeito aos elos produtivos construídos e, portanto, em relação à capacidade de gerar encadeamentos a montante e a jusante em sua cadeia produtiva. Dentro desta perspectiva, vislumbra-se a ameaça do país se tornar exportador de óleo bruto e importador de derivados, justamente quando se depara com uma oportunidade ímpar para o adensamento dessa cadeia produtiva a partir da descoberta do pré-sal.

Como sugestão para trabalhos futuros seria interessante analisar as especificidades (técnicas e econômicas) do setor brasileiro de refino e da política adotada na atualidade pela Petrobras, caracterizada pela redução no fator de utilização das plantas de refino, venda de ativos e política de alinhamento com os preços internacionais. Além desses temas, salta aos olhos a importância da realização de estudos com vistas a avaliar alternativas à atual política de preços de combustíveis, que não prejudiquem a Petrobras e tampouco a sociedade brasileira.

\section{REFERENCIAL BIBLIOGRAFICO}

AGÊNCIA NACIONAL DO PETRÓLEO (RJ). Anuário estatístico 2010 e 2017. Disponível em: <http://www.anp.gov.br/wwwanp/publicacoes/anuario-estatistico/3819anuario-estatistico-2017> Acesso em: 22 fev. 2018.

ALMEIDA, E. L. F. de; OLIVEIRA, P. V. de; LOSEKANN, Luciano. Impactos da contenção dos preços de combustíveis no Brasil e opções de mecanismos de precificação. Brazilian Journal of Political Economy, v. 35, n. 3, p. 531-556, 2015.

ALMEIDA, E.; LOSEKANN, L.; VITTO, WAC. Custos e benefícios da atual política de conteúdo local. Rio de Janeiro, 2016.

ALMEIDA, Jorge. Introdução à indústria do petróleo. Petrobras - Petróleo Brasileiro S.A. 2006.

BALESTRO VILlAMIL, Moisés et al. A experiência da Rede PETRO-RS: uma Estratégia para o Desenvolvimento das Capacidades Dinâmicas. RAC-Revista de Administração Contemporânea, v. 8, n. Esp, 2004.

BASTOS, Emanuelle de Souza; ROSA, Maycon Peter da; PIMENTA, Márcio Marvila. Os Impactos da Operação Lava Jato e da Crise Internacional do Petróleo nos Retorno Anormais e Indicadores Contábeis da Petrobras 2012-2015. Pensar Contábil, v. 18, n. 67, 2017.

BARBOZA, A. C. Análise de investimentos em refino na Petrobras em ambiente concorrencial. Tese de Doutorado. Tese de M. Sc. COPPE/UFRJ, Rio de Janeiro, Brasil, 1996.

BERATELLI JÚNIOR, A. A., et. al. Interdependência e encadeamento das exportações setoriais e os modais de transporte: um enfoque insumo produto. Revista econômica do nordeste. 2010

COSTA, Thor Henrique Brito da. Estratégias de diversificação: uma abordagem heterodoxa sobre o setor de petróleo. 2014. 
FELIPE, Ednilson S. Mudanças institucionais e estratégias empresariais: a trajetória e o crescimento da Petrobras a partir da sua atuação no novo ambiente competitivo (1997-2010). Rio de Janeiro: UFRJ/IE, 2010.

FURTADO, André Tosi. A trajetória tecnológica da Petrobrás na produção offshore. Revista Espacios, v. 17, n. 3, 1996.

GUILHOTO. J. J.M. Análise de insumo e Produto: Teoria e Fundamentos. Apostila de conceitos básicos de Insumo e Produto. USP. 2004.

HIRSCHMAN, A. O. The strategy of economy development. London, 1958

LUCCHESI, Celso Fernando. Petróleo. Estudos avançados, v. 12, n. 33, p. 17-40, 1998.

MILLER, R.E; BLAIR, P.D. Input-output analysis: foundations and extensions. EnglewoodCliffs, New Jersey: Prentice-Hall, Inc., 2009. 464p.

OLIVEIRA, Adilson de. Indústria Para-Petrolífera Brasileira Competitividade, Desafios e Oportunidades. Rio de Janeiro, IE/UFRJ. Disponível em: $<$ http://www. ie. ufrj. br/datacenterie/pdfs/seminarios/pesquisa/texto1811. pdf, 2008.

PETROBRAS. Relatório de Administração 2006. 2009. 2010. 2014. 2016. 2017. Disponível em: <http://www.investidorpetrobras.com.br/pt/relatorios-anuais/relatoriode-administracao> Acesso em 22 fev. 2018.

PINTO JÚNIOR, Helder Queiroz et al. Economia da indústria do petróleo. In: PINTO JÚNIOR, Helder Queiroz (org.). Economia da energia: fundamentos econômicos, evolução histórica e organização industrial. Rio de Janeiro: Elsevier, p. 43-128, 2007.

PIQUET, Rosélia Périssé; HASENCLEVER, Lia; SHIMODA, Eduardo. O desenvolvimento e a política de conteúdo local na indústria petrolífera: visões divergentes. Revista Tecnologia e Sociedade, v. 12, n. 24, 2016.

PROCHNIK, Victor. A política de conteúdo local na indústria de petróleo e gás: o caso dos fornecedores de equipamentos de instrumentação e automação. XV altEc, Portugal, 2013.

RAMALHO, André; Polito, Rodrigo. Petrobras busca parceria para reduzir fatia de mercado em refino. Valor Econômico, 19 abr. 2018. Disponível em: < http://www.valor.com.br/empresas/5466273/petrobras-busca-parceria-para-reduzirfatia-de-mercado-em-refino>. Acesso em: 30 mai. 2018.

RAPPEL, Eduardo. Oportunidades e desafios do parque nacional de fornecedores de bens e serviços para o setor de petróleo e gás. In: PIQUET, Rosélia; (orgs.). Petróleo, Royaties e Região. Rio de Janeiro: Garamond, p. 95-120, 2003.

RASMUSSEN, Poul Nørregaard. Studies in inter-sectoral relations. E. Harck, 1956.

SILVA, Cássio R. S. da. Compras Governamentais e Aprendizagem Tecnológica: Uma análise da política de Compras da Petrobras para seus empreendimentos offshore. Tese de Doutorado apresentada no Instituto de Geociências, Departamento de Política Científica e Tecnológica, Universidade Estadual de Campinas. 2009

SILVA, Cássio Garcia Ribeiro Soares da; FURTADO, André Tosi. Uma análise da nova política de compras da PETROBRAS para seus empreendimentos offshore. Revista Gestão Industrial, v. 2, n. 3, 2006.

SANTOS, Ricardo José dos; AVELLAR, Ana Paula Macedo de. Da criação do conselho nacional do petróleo à política de conteúdo local: a trajetória histórica das políticas 
para a indústria do petróleo e gás natural no Brasil. História econômica \& história de empresas vol. 19 no 1, 221-248, 2016.

TAKASAGO, Milene; MOLLO, Maria de Lourdes Rollemberg; GUILHOTO, Joaquim JM. O debate desenvolvimentista no Brasil: discutindo resultados da matriz de insumo-produto. Planejamento e Políticas Públicas, n. 48, 2017. 